\title{
Evaluation of isosorbide-5-mononitrate as a cervical ripening agent prior to induced abortion in contrast to misoprostol- a randomized controlled trial
}

\author{
De Aloke Kumar ${ }^{1}$, Bhattacharyya Sanjoy Kumar ${ }^{1}$, Chakraborty Aparna', Samanta Amrita² \\ Departments of ${ }^{1}$ Gynecology and Obstetrics, ${ }^{2}$ Community Medicine, R G Kar Medical College, Kolkata, West Bengal, India
}

\section{Objective}

To determine whether vaginal application of $40 \mathrm{mg}$ isosorbide-5-mononitrate (ISMN) has a comparable cervical ripening efficacy to and lesser side effects than $400 \mu \mathrm{g}$ misoprostol in women scheduled for the first trimester induced abortion using a manual vacuum aspirator (MVA).

\section{Methods}

We conducted a prospective randomized open-label study in 70 women at 6-12 weeks of pregnancy at the R G Kar Medical College and Hospital, Kolkata, India, over a period of two years from 2015 to 2017. Forty milligrams of ISMN and $400 \mu \mathrm{g}$ misoprostol were vaginally applied for cervical priming. The primary outcome measure was the cervical response assessed by the passage of the appropriate and largest sized MVA cannula through the internal os without resistance, at the beginning of the procedure.

\section{Results}

The base line cervical dilatation was found to be significantly higher in the misoprostol group than in the ISMN group ( $7.65 \pm 1.38$ vs. $6.9 \pm 1.26 \mathrm{~mm} ; P=0.025,95 \%$ confidence interval, -1.4046 to -0.953$)$. However, when the women were sub-analyzed based on parity, there was no statistically significant difference in the same parameters among the multigravid women. The need for further cervical dilatation was significantly higher in the ISMN group when the primigravid women were compared, although the multigravid women responded favorably to ISMN.

\section{Conclusion}

In the primigravid women, misoprostol appears to exert a higher efficacy as a cervical ripening agent in contrast to ISMN. However, ISMN can be used in multigravid women for the same purpose as in this group, misoprostol did not show any significant improvement in efficacy over ISMN.

Keywords: Cervical ripening; Isosorbide-5-mononitrate; Induced abortion

\section{Introduction}

The Millennium Development Goal 5 (MDG 5) enjoins India to reduce the maternal mortality ratio (MMR) in the country by three quarters. Between 1990 and 2015, there is a gradual yet steady decline in MMR from 398 per 100,000 live births in 1997-1998 to 178 in 2010-2012 and 174 in 2017 [1]. While evaluating the causes of maternal deaths, it is rather worrisome that in spite of the liberal provisions of the Medical Termination of Pregnancy (MTP) Act, unsafe abortion still continues to be a major reason contributing to a large number of maternal deaths in India [2]. The pos-
Received: 2018.10.19. Revised: 2019.01.03. Accepted: 2019.03.25. Corresponding author: Bhattacharyya Sanjoy Kumar Department of Obstetrics and Gynecology, R G Kar Medical College, 17 Naktala Road, Kolkata, West Bengal 700047, India E-mail: sanjay.krbhattacharyya@gmail.com https://orcid.org/0000-0002-2085-1342

Articles published in Obstet Gynecol Sci are open-access, distributed under the terms of the Creative Commons Attribution Non-Commercial License (http://creativecommons. org/licenses/by-nc/3.0/) which permits unrestricted non-commercial use, distribution, and reproduction in any medium, provided the original work is properly cited.

Copyright $\odot 2019$ Korean Society of Obstetrics and Gynecology 


\title{
Obstetrics \& Gynecology Science
}

\author{
Vol. 62, No. 5, 2019
}

sible explanation behind this is manifold, especially in rural areas. Apart from the lack of awareness or access to abortion care services, lack of trained and certified providers of MTP in public health facilities is one of the major reasons. Considering this fact, a nationwide strategic approach was undertaken under the Reproductive, Maternal, Child and Adolescent Health ( $\mathrm{RMNCH}+\mathrm{A})$ to provide a Comprehensive Abortion Care (CAC) training to health personals, so that they can render this service at the appropriate level of public health facilities [3]. The requisite teaching regarding the CAC services includes hands-on-training for performing medical terminations up to 12 weeks by using a manual vacuum aspirator (MVA). MVA is a safe and effective method for abortion that involves evacuation of the uterine contents by the use of a hand-held plastic aspirator without the need for any electrical connection or pre-surgical cervical preparation as a protocol.

This training is ongoing in all the medical colleges in India including R G Kar Medical College, Kolkata, India from 2010 to till date [4]. Being the facilitators of the said program, we keep in constant touch with the providers who received training from us. They regularly update us regarding any technical difficulties they face in their workplace while performing MTPs with MVA. Throughout this journey and over a period of several years, we have noted that difficulty in inserting the cannula through an unripe cervix is the most commonly encountered problem as this training does not recommend any pre-surgical ripening or dilatation of the cervix. This problem is more commonly encountered when the client is a nulliparous or carrying a post-cesarean section pregnancy. This particular problem leads not only to the dissatisfaction of clients regarding this procedure due to discomfort and pain but also results in loss of confidence in the providers, thereby hampering the ultimate goal of the program. This feedback compels us to think about the need for pre-surgical ripening before performing MVA, going beyond the stringent program guideline, so that the job becomes practically feasible.

Misoprostol tablet was tried successfully as a pre-surgical ripening agent in similar circumstances and we initially advocated our trainers to use it before performing the procedure. But misoprostol has various side effects ranging from nausea, vomiting, diarrhea, fever and quite expectedly, we got feedbacks regarding arousal of a widespread hostility among our clients to accept misoprostol. We realized that, as our target population is comprised of uneducated rural women, there is a need for another pre-operative cervical ripening agent that is both clinically effective and has a lower incidence of adverse effects than misoprostol.

Nitric oxide (NO) donors are now gaining popularity as cervical priming agents [5]. The NO generating system is present in the cervix. Human studies using NO donors have shown that they are effective for cervical priming before the firsttrimester surgical abortion and have minimal adverse effects. We thought about this priming agent, considering whether it can be recommended as a pre-surgical ripening agent in place of misoprostol. This incited in our mind the need for a comparative study to evaluate the efficacy as well as adverse effects of a NO donor isosorbide-5-mononitrate (ISMN) as a pre-surgical ripening agent in contrast to misoprostol before performing MVA.

\section{Materials and methods}

\section{Study design}

This prospective randomized open- label study was carried out in R G Kar Medical College and Hospital, Kolkata, India over a period of two years from 2015 to 2017. Seventy healthy women between the ages of 18-38 years with 6-12 weeks of pregnancy and requesting termination of pregnancy were included. The clinical responses of the two drugs, 40 mg ISMN vs. $400 \mu \mathrm{g}$ misoprostol, applied vaginally, were compared. The indications of termination of pregnancy were as per the MTP Act [6]. Informed consent from all the women was obtained before enrolment and the study was approved by the ethical committee of the R G Kar Medical College and Hospital.

\section{Study population}

Seventy women at 6-12 weeks of gestation and scheduled to have surgical termination of pregnancy by MVA were included in this study after fulfilling the inclusion and exclusion criteria. The exclusion criteria were women with multiple pregnancies, baseline hemoglobin level of $<8 \mathrm{~g} / \mathrm{dL}$, maternal local or systemic infection, and any degree of cervical dilatation suggestive of an already ongoing abortion process. We also excluded women who had any pulmonary, hepatic, renal, and cardiovascular disease. 


\section{Obstetrics \& Gynecology Science}

De Aloke Kumar, et al. Isosorbide-5-mononitrate as a cervical ripening agent

\section{Study interventions}

The women scheduled to have surgical abortions were admitted at 7 AM following clinical examination and detailed history taking. Routine baseline investigations were also performed. Those women who received ISMN tablets were enrolled in group $\mathrm{A}$ (study group) and those who received misoprostol tablets were enrolled in group B (control group) by the doctors who administered the tablets but ultimately did not assess the treatment outcomes. In group A, $40 \mathrm{mg}$ ISMN (two $20 \mathrm{mg}$ tablets) and in group B, $400 \mu \mathrm{g}$ misoprostol (two $200 \mu \mathrm{g}$ tablets) were placed into the posterior vaginal fornix 3 hours prior to surgical termination of pregnancy by MVA. The outcome assessors were blinded of the treatment allocation.

The operative procedure was performed after 3 hours of drug administration without using any analgesia or anesthesia. The cervical response was assessed by the passage of the appropriate and largest size MVA cannula (any of the above sizes as per the following chart, passing through the internal os without any resistance) at the beginning of the procedure. The MVA cannula has sizes of 4, 5, 6, 7, 8, 9, 10, and 12 . The recommendation of inserting or attempting to insert the cannula was followed according to the direction of the CAC program [4].

\begin{tabular}{|l|c|}
\hline Uterine size & Suggested cannula size $(\mathrm{mm})$ \\
\hline $4-6$ weeks LMP & $4-6$ \\
\hline 7-9 weeks LMP & $6-8$ \\
\hline $10-12$ weeks LMP & $8-10$ \\
\hline
\end{tabular}

Initially, the widest cannula from the range appropriate to the gestational age was selected and if the provider felt the slightest resistance during the introduction, he/she shifted gradually to the one at the lower end of the range, and the number of the latter was noted. If the provider felt dilatation was inappropriate and even the narrowest cannula of the range could not be passed with ease in the first attempt, the lower sized cannula was selected. In that case, the cannula size was noted as the primary dilatation and the woman was considered and counted for further dilatations. Further dilatation up to the desired size as per the chart was performed to complete the procedure.

Those patients who complained of moderate to severe pain (visual analog scale [VAS] score $\geq 5$ ) received intravenous pentazocine and diazepam injection for analgesia during the procedure following assessment of the preliminary cervical dilatation [7]. The time taken to complete the procedure was calculated with the help of a stopwatch. The counting was started from the first introduction of the cannula and ended with inspection of the area by the provider at the end of the procedure when she/he declared that there was no bleeding from the os or the bleeding was within an acceptable range.

\section{Randomization}

The women were divided into 2 groups ( $A$ and $B$ ) using a computer-generated randomized protocol with 35 women in each arm. We used a computer- generated randomization sequence to assign the participants into 2 treatment groups and the allocation was concealed in sealed, sequentially numbered, brown opaque envelopes; which were prepared by the statistician of this institution and handed over to the Pharmacy Department. The researchers responsible for treating the women allocated the next available number on entry into the trial in the Department of Obstetrics and Gynecology. Each woman collected the corresponding sealed envelope directly from the Pharmacy Department. The envelope was opened just before administration of the drug by the on-duty doctors and the drug was administered as per the mentioned code. Because of the nature of the drug administration, the patients were blinded, but the doctors responsible for the drug administration were not blinded to the allocated treatment (Fig. 1).

\section{Study outcomes}

The primary outcome measure was the cervical response assessed by the passage of the appropriate and largest size MVA cannula (any of the above sizes as per the chart) through the internal os without any resistance at the beginning of the procedure. If the provider felt that dilatation was inappropriate and even the narrowest cannula of the range could not be passed with ease in the first attempt, the lower sized cannula was selected. In that case, the cannula size was noted as the primary dilatation and the woman was counted for further dilatations. Further dilatation up to the desired cannula size as per the chart was performed.

The secondary outcome measures were, need for further cervical dilatation, subjective assessment of pain during dilatation using VAS, and time taken to complete the procedure. Development of any preoperative adverse effects like nausea, vomiting, abdominal cramp, vaginal bleeding, pyrexia of sig- 


\section{Obstetrics \& Gynecology Science}

Vol. 62, No. 5, 2019

nificance, loose motion, headache, dizziness, etc. was noted and recorded. The women were asked to report to the residents and nurses when they had any such symptoms following administration of the drugs. Per-operative complications like cervical injury and uterine perforation, if any, was also taken into consideration and recorded.

\section{Sample size calculation and statistical analysis}

The difference in the mean baseline cervical dilation achieved 3 hours after application of the cervical priming agent was used to calculate the sample size. From a previous study, the mean baseline cervical dilatation achieved 3 hours after intravaginal application of $400 \mu \mathrm{g}$ misoprostol as a cervical ripening agent for surgical termination of the first-trimester pregnancy was $7.84 \mathrm{~mm}$ (standard deviation, 2.9) [8]. A difference of $1.5 \mathrm{~cm}$ in the mean baseline cervical dilatation using $40 \mathrm{mg}$ ISMN vaginally was considered clinically significant. Therefore, a sample size of 30 in each arm was calculated to have a power of $80 \%$ at a $5 \%$ significance level to detect such a difference in the mean baseline cervical dilatation. Assuming that $15 \%$ of the subjects' data could not be used for analysis, the total number of subjects required was calculated to be 35 in each arm.

All data entries were visually double-checked by an independent second investigator. The data were analyzed using medical statistical software (SPSS software; IBM Corp., Armonk, NY, USA). Statistical analysis included $\chi^{2}$ test, $t$-test, $F$ test, and Mid $P$ exact tests were used to compare the outcomes between the study and the control groups. A $P$-value of $<0.05$ was considered statistically significant.

\section{Results}

\section{Study population}

Table 1 shows the demographic characteristics of the 2 groups. The mean age of the subjects was comparable $(24.7 \pm 3.1$ years in the ISMN group [group A] and $25.1 \pm 3.3$
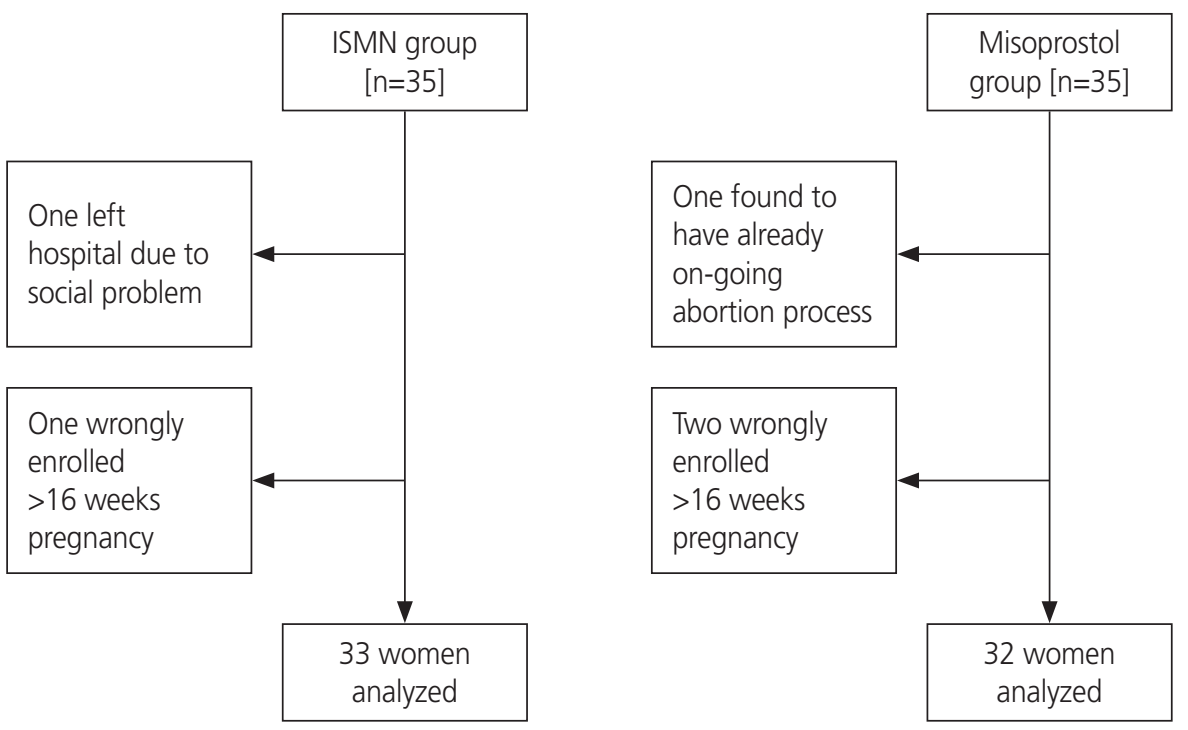

Fig. 1. Study flow chart. ISMN, isosorbide5-mononitrate.

Table 1. Demographic characteristics of the studied patients

\begin{tabular}{lccc}
\hline Characteristic & ISMN group/group A $(\mathbf{n}=\mathbf{3 3})$ & Misoprostol group/group B $(\mathbf{n}=\mathbf{3 2})$ & $\boldsymbol{P}$-value \\
\hline Age $(\mathrm{yr})$ & $24.7 \pm 3.1$ & $25.1 \pm 3.3$ & 0.728 \\
Primigravida & $11(33.33 \%)$ & $12(37.50 \%)$ & 0.734 \\
Multigravida & $22(66.67 \%)$ & $20(63.50 \%)$ & 0.734 \\
BMI(kg/m²) & $23.3 \pm 0.85$ & $22.7 \pm 0.92$ & 0.658 \\
Gestational age (wk) & $7.4 \pm 0.89$ & $7.1 \pm 0.93$ & 0.805 \\
\hline
\end{tabular}

The results are expressed as the mean \pm standard deviation or number (\%).

ISMN, isosorbide-5-mononitrate; BMI, body mass index. 


\section{Obstetrics \& Gynecology Science}

De Aloke Kumar, et al. Isosorbide-5-mononitrate as a cervical ripening agent

years in the misoprostol group [group B]). The distribution of the subjects on the basis of parity and gestational age at which termination was performed was also comparable between the 2 groups.

\section{Baseline cervical dilatation}

Table 2 demonstrates the comparative analysis of the baseline cervical dilatation 3 hours following administration of the cervical priming agent. The mean base line cervical dilatation achieved 3 hours after administration of the cervical priming agent was significantly higher in the misoprostol group as

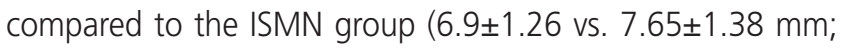
$P=0.025 ; 95 \%$ confidence interval $[\mathrm{Cl}],-1.4046$ to -0.953$)$. This is a composite result irrespective of the parity. While looking into the subgroups, there appears no statistically significant difference in the mean cervical dilatation in the multigravid women than the primigravid ones $(7.3 \pm 1.31$ vs. $7.8 \pm 1.42 \mathrm{~mm} ; P=0.242 ; 95 \% \mathrm{Cl},-1.3513$ to 0.3513$)$. However, in the primigravid women, misoprostol worked better with a significantly higher rate of cervical dilatation at 3 hours.

\section{Further cervical dilatation}

The second part of Table 2 shows a comparative analysis of the need for further cervical dilatation. The need for further cervical dilatation was comparable between the 2 groups and did not appear significantly different irrespective of the cervical priming agent used $(P=0.150)$. However, the need was significantly higher in the ISMN group when the primigravid women were compared separately (8/11 vs. 3/12; $P=0.032$; relative risk, $2.909 ; 95 \% \mathrm{Cl}, 1.024$ to 8.268$)$. The multiparous women did not behave differently in respect to the cervical priming agent used, and the need for further dilatation did not appear significantly different in both the groups ( $P=0.877)$.

\section{Pain perception}

Table 3 compares the subjective assessment of pain in both groups. Thirteen out of 33 women in group A (ISMN group) and 8 out of 33 women in group B (misoprostol group) complained of moderate to severe pain during the procedure. However, this result was statistically insignificant. While comparing the subgroups, a significantly higher number of primigravid women in group A complained moderate to severe pain during the procedure in contrast to the women in group B.

\section{Preoperative adverse effects}

Table 4 shows the comparison between the incidence of preoperative adverse effects and per-operative complications between the 2 groups. Majority of the women, irrespective of the priming agent, expressed no discomfort (23/33 vs. 18/32). Nausea and vomiting, abdominal cramp, and loose motion were noted in a few women in the misoprostol

Table 2. Comparison of the outcomes following pre-surgical ripening

\begin{tabular}{|c|c|c|c|c|c|}
\hline Results & $\begin{array}{c}\text { ISMN group/group } \\
\text { A }(n=33)\end{array}$ & $\begin{array}{l}\text { Misoprostol group/ } \\
\text { group } B(n=32)\end{array}$ & $\mathbf{R R}$ & $95 \% \mathrm{Cl}$ & $P$-value \\
\hline \multicolumn{6}{|c|}{ Baseline cervical dilatation(cm) } \\
\hline Primigravid & $6.1 \pm 1.21$ & $7.4 \pm 1.33$ & - & -2.4061 to -0.1938 & 0.023 \\
\hline Multigravid & $7.3 \pm 1.31$ & $7.8 \pm 1.42$ & - & -1.3513 to 0.3513 & 0.242 \\
\hline Total & $6.9 \pm 1.26$ & $7.65 \pm 1.38$ & - & -1.4046 to -0.953 & 0.025 \\
\hline \multicolumn{6}{|c|}{ Further cervical dilatation required (no) } \\
\hline Primigravid & $8 / 11$ & $3 / 12$ & 2.909 & 1.024 to 8.268 & 0.032 \\
\hline Multigravid & $6 / 22$ & $5 / 20$ & 1.091 & 0.3931 to 3.027 & 0.877 \\
\hline Total & $14 / 33$ & $8 / 32$ & 1.697 & 0.8262 to 3.485 & 0.150 \\
\hline \multicolumn{6}{|c|}{ Time required for operative procedure(min) } \\
\hline Primigravid & $5.32 \pm 1.06$ & $4.41 \pm 1.01$ & - & 0.0123 to 1.8076 & 0.047 \\
\hline Multigravid & $4.91 \pm 1.06$ & $4.32 \pm 1.06$ & - & -0.0526 to 1.2326 & 0.070 \\
\hline Total & $5.04 \pm 1.06$ & $4.35 \pm 1.06$ & - & 0.1744 to 1.2055 & 0.009 \\
\hline
\end{tabular}

ISMN, isosorbide-5-mononitrate; $\mathrm{RR}$, relative risk; $\mathrm{Cl}$, confidence interval. 


\section{Obstetrics \& Gynecology Science}

Vol. 62, No. 5, 2019

Table 3. Subjective assessment of pain during cervical dilatation

\begin{tabular}{|c|c|c|c|c|c|}
\hline Pain (VAS score) & $\begin{array}{c}\text { ISMN group/group } \\
\text { A (n=33) }\end{array}$ & $\begin{array}{l}\text { Misoprostol group/ } \\
\text { group } B(n=32)\end{array}$ & $\mathbf{R R}$ & $95 \% \mathrm{Cl}$ & $P$-value \\
\hline No discomfort (0) & 12 & 14 & - & - & 0.556 \\
\hline Mild discomfort(1-2) & 5 & 7 & - & - & 0.507 \\
\hline Mild pain (3-4) & 3 & 3 & - & - & 0.970 \\
\hline $\begin{array}{l}\text { Moderate to severe pain requiring } \\
\text { analgesia/anaesthesia(5-10) }\end{array}$ & 13 & 8 & & & \\
\hline Primigravid & $8 / 11$ & $3 / 12$ & 2.909 & 1.024 to 8.268 & 0.032 \\
\hline Multigravid & $5 / 22$ & $5 / 20$ & 0.909 & 0.3082 to 2.681 & 0.869 \\
\hline Total & $13 / 33$ & $8 / 32$ & 0.909 & 0.3082 to 2.681 & 0.389 \\
\hline
\end{tabular}

VAS, visual analog scale; ISMN, isosorbide-5-mononitrate; RR, relative risk; Cl, confidence interval.

Table 4. Adverse effects (pre-operatively) and complications (per-operatively)

\begin{tabular}{lccc}
\hline Variables & ISMN group/group A $(\mathbf{n = 3 3 )}$ & Misoprostol group/group B $(\mathbf{n}=\mathbf{3 2})$ & $\boldsymbol{P}$-value \\
\hline Pre-operative side effects & & & 0.279 \\
No side effects & 23 & 18 & 0.348 \\
Nausea \& vomiting & 1 & 3 & - \\
Abdominal cramp & 0 & 4 & - \\
Loose motion & 0 & 2 & - \\
Pyrexia of significance & 0 & 0 & 0.248 \\
Vaginal bleeding (mild) & 2 & 5 & 0.118 \\
Headache & 5 & 1 & - \\
Dizziness & 2 & 0 & - \\
Flushing & 1 & 0 & 0.636 \\
Per-operative complication & & & 0.636 \\
No complication & 31 & 31 & - \\
Cervical Injury & 2 & 1 & 0 \\
Uterine perforation & 0 & 0 & \\
\hline
\end{tabular}

ISMN, isosorbide-5-mononitrate.

group whereas headache, dizziness, and flushing appeared more common in the ISMN group. However, none of these adverse effects were significantly different.

\section{Discussion}

Apart from prostaglandin, which plays a crucial role in cervical priming, NO, a free radical gas with a short half-life of 4 seconds, is also thought to be one of the fundamental mediators of cervical ripening. Several NO donors, such as like ISMN, glyceryl trinitrate, and sodium nitroprusside have been reported to reduce cervical resistance [9]. Among these agents, we have chosen ISMN as a priming agent as it is available in tablet form, cheap, easy to administer, and widely available.

We have designed to perform the procedure 3 hours following vaginal application of $400 \mu \mathrm{g}$ of misoprostol or $40 \mathrm{mg}$ ISMN. The dose of misoprostol and the waiting time following drug administration were decided in accordance with a previous study [10]. The author recommended that a time frame of 3 hours is necessary to obtain the full effects of misoprostol applied either orally or vaginally. Either increasing the dose to $>400 \mu \mathrm{g}$ or escalating the interval beyond 3 hours does not seem to have any additional effects over agents causing cervical dilatation but potentiates the adverse 


\section{Obstetrics \& Gynecology Science}

De Aloke Kumar, et al. Isosorbide-5-mononitrate as a cervical ripening agent

effects of misoprostol [11]. The vaginal application is also found to have greater efficacy than oral application [12], although a previous study has found no difference in this regard [13].

The dose of ISMN (40 mg) was in accordance with the study of Soliman who compared ISMN, misoprostol, and combination therapy of both for pre-induction cervical ripening at term [14]. The comparative dose of misoprostol was also in accordance with similar other studies which showed that the lowest misoprostol dose of $200 \mu \mathrm{g}$ has a significantly lower efficacy, whereas, doses $>400 \mu \mathrm{g}$ leads to increased adverse effects $[15,16]$. Therefore $400 \mu \mathrm{g}$ misoprostol was chosen as an optimum comparative dose [17].

Our results showed that misoprostol is a better cervical priming agent than ISMN for the first- trimester surgical abortion irrespective of parity. All other similar studies confirmed the better priming effects of misoprostol on the gravid cervix, and thus, it was not an unexpected outcome $[18,19]$. However, we analyzed our study outcome a bit differently. As our clients were mainly multigravid women, we further sub-analyzed the study outcome parity-wise. We found that ISMN demonstrated almost equivalent priming effect in contrast to misoprostol when only multigravid women were included. Thus, although primigravid women responded better to misoprostol, ISMN did not demonstrate a lower efficacy than misoprostol in the multigravid women.

Failure to achieve optimal dilatation is another point to consider as this outcome also reflected the drug-potency. Fourteen women in the ISMN group (14/33) and 8 in the misoprostol group (8/32) could not achieve the expected cervical dilatation as per the gestational age chart and needed further dilatation. This comparison was found to be statistically insignificant. However, in the parity-wise subgroupdata, a statistically higher number of primigravid women in the ISMN sub-group needed further dilatation, in contrast to the misoprostol group.

The procedure was intended to undergo without anesthesia. Thus, the time required to complete the procedure is an important outcome measure as the subjects, especially in a fully conscious state, often feel very uncomfortable in the lithotomy position. Our study results showed that the surgeons needed significantly lesser time to complete the procedure in the misoprostol group than in the ISMN group. However, during parity-wise evaluation, the time taken to complete the procedure in the multigravid women appears almost equal in both the groups and the time difference appeared statistically insignificant. This is in accordance with the previous chart regarding the baseline cervical dilatation which showed that the multigravid women responded more favorably to ISMN than the primigravid ones and the majority of women in this group needed no additional cervical dilatation. This could be a possible explanation of why there was no significant difference in the observed procedural timings while comparing the data of multigravid women in both groups.

Pain perceived during the procedure was another factor under our consideration as pain was inversely related to the ease of dilatation of the cervix. This factor affects the acceptability of the method in rural settings. Overall, 13 women in the ISMN group and 8 women in the misoprostol group perceived moderate to severe pain during the procedure and subsequently needed analgesia/anesthesia. However, the difference between the 2 groups regarding pain perception appeared statistically insignificant. On the contrary, in the parity-wise sub-analysis, the primigravid women showed significantly poor tolerance to pain who received ISMN in contrast to misoprostol. However, the multigravid women showed no such significant difference in pain perception in the sub-group analysis.

This study was initiated considering the adverse effects of misoprostol which turns this drug unpopular among the women. A study conducted by Tang showed that 32-57\% of the women suffered from fever and chill following $400 \mu \mathrm{g}$ misoprostol administration when used for controlling postpartum hemorrhage [11]. Our study, however, showed, that a majority of the women in both the groups did not experience any adverse effects. Few episodes of nausea, vomiting, abdominal cramps, and bleeding were common in women who were administered with misoprostol, while headache and dizziness were common in women who were administered with ISMN, although the results were not significantly different. Ei-Khayat et al. [20] showed that out of the 162 subjects, a significantly higher incidence of pain was perceived in the misoprostol group and a significantly higher incidence of headache was perceived in the ISMN group. This is not unlikely as misoprostol has an additional potency for uterine contraction apart from ripening of the cervix, whereas, ISMN is a vasodilator and only a priming agent. Dhillon et al. [21] in their study involving 25 women in each group also showed that headache was statistically higher in 


\section{Obstetrics \& Gynecology Science}

Vol. 62, No. 5, 2019

the ISMN group than the misoprostol group. Similar findings were also shown by Duhan et al. [22]. However, this present study fails to demonstrate any significantly higher incidence of headache in the ISMN group.

Finally, this study showed that misoprostol is invariably a better priming agent than ISMN. However, multigravid women responded more favorably to ISMN than the primigravid women and ISMN worked almost as well as misoprostol. The surgeons were comfortable with the adequate dilatation achieved in the multigravid women administered ISMN; similar adverse effects were observed and the procedure could be completed within a similar timeframe. Thus, we can conclude that ISMN can be used as a cervical ripening agent instead of misoprostol while performing abortion in multigravid women. Contrary to our feedback as well as other study findings, neither misoprostol nor ISMN showed any major statistically significant adverse effects in either of the groups. Probably our sample size was not powered enough to draw a conclusion for any of the secondary outcomes and this might have played a crucial role in explaining why our study was unable to demonstrate any appreciable adverse effects with any of the drugs. Further study should be performed with a larger sample size to draw a conclusion regarding the different secondary outcomes, especially the adverse effects of the 2 drugs.

This study has a few other limitations. First, the procedures were performed by different surgeons according to the duty-rosters. Thus, we could not rule out the inter-observer variations in the study results, as quite expectedly, each surgeon works and reacts differently while performing a similar procedure. Second, one of the initial feedbacks we received was regarding the incidence of difficult cannulation in postcesarean pregnancies. Despite this fact, in this present study, we could not differentiate the post- cesarean pregnancies, and thus, we are now unable to comment separately on them. Though, as a whole, we found that the multigravid women responded better to ISMN than to misoprostol, we are uncertain whether the same applies when the client is a multigravid woman with a post-cesarean pregnancy.

\section{Conflict of Interest}

The authors certify that they have no affiliations with or involvement in any organization or entity with any financial interest (such as honoraria; educational grants; participation in speakers' bureaus; membership, employment, consultancies, stock ownership, or other equity interest; and expert testimony or patent-licensing arrangements), or non-financial interest (such as personal or professional relationships, affiliations, knowledge or beliefs) in the subject matter or materials discussed in this manuscript.

\section{Ethical approval}

All procedures in studies involving human participants were performed in accordance with the ethical standards of the institutional and/or national research committee and with the 1964 Helsinki declaration and its later amendments or comparable ethical standards. Informed consent from all the women was obtained before enrolment and the study was approved by the Ethical Committee of the R G Kar Medical College and Hospital.

\section{Patient consent}

Informed consent was obtained from all individual participants included in the study.

\section{Acknowledgements}

The authors thank Professor Rajendra Prasad Ganguly, Department of Gynecology and Obstetrics, R G Kar Medical College, Kolkata, India.

\section{References}

1. Pandve HT. Health-related millennium development goals: how much India has progressed? Arch Med Health Sci 2015;3:335-9.

2. Say L, Chou D, Gemmill A, Tunçalp Ö, Moller AB, Daniels J, et al. Global causes of maternal death: a WHO systematic analysis. Lancet Glob Health 2014;2:e323-33.

3. Ministry of Health \& Family Welfare Government of India. A strategic approach to reproductive, maternal, child and adolescent health $(\mathrm{RMNCH}+\mathrm{A})$ in India. New 


\section{Obstetrics \& Gynecology Science}

De Aloke Kumar, et al. Isosorbide-5-mononitrate as a cervical ripening agent

Delhi: Ministry of Health \& Family Welfare Government of India; 2013.

4. Banerjee SK, Andersen KL, Buchanan RM, Warvadekar J. Woman-centered research on access to safe abortion services and implications for behavioral change communication interventions: a cross-sectional study of women in Bihar and Jharkhand, India. BMC Public Health 2012;12:175.

5. Li CF, Chan CW, Ho PC. A study of the efficacy of cervical ripening with nitric oxide donor versus placebo for cervical priming before second-trimester termination of pregnancy. Contraception 2003;68:269-72.

6 . Hirve SS. Abortion law, policy and services in India: a critical review. Reprod Health Matters 2004;12:114-21.

7. McCormack HM, Horne DJ, Sheather S. Clinical applications of visual analogue scales: a critical review. Psychol Med 1988;18:1007-19.

8. Saxena P, Salhan S, Sarda N. Sublingual versus vaginal route of misoprostol for cervical ripening prior to surgical termination of first trimester abortions. Eur J Obstet Gynecol Reprod Biol 2006;125:109-13.

9. Ghosh A, Lattey KR, Kelly AJ. Nitric oxide donors for cervical ripening and induction of labour. Cochrane Database Syst Rev 2016;12:CD006901.

10. Fiala C, Gemzell-Danielsson K, Tang OS, von Hertzen $\mathrm{H}$. Cervical priming with misoprostol prior to transcervical procedures. Int J Gynaecol Obstet 2007;99 Suppl 2:S168-71.

11. Tang OS, Gemzell-Danielsson K, Ho PC. Misoprostol: pharmacokinetic profiles, effects on the uterus and sideeffects. Int J Gynaecol Obstet 2007;99 Suppl 2:S160-7.

12. Maclsaac L, Grossman D, Balistreri E, Darney P. A randomized controlled trial of laminaria, oral misoprostol, and vaginal misoprostol before abortion. Obstet Gynecol 1999;93:766-70.

13. Ashok PW, Flett GM, Templeton A. Mifepristone versus vaginally administered misoprostol for cervical priming before first-trimester termination of pregnancy: a randomized, controlled study. Am J Obstet Gynecol
2000;183:998-1002.

14. Soliman AT. A comparison of isosorbide mononitrate, misoprostol, and combination therapy for preinduction cervical ripening at term: a randomized controlled trial. Tanta Med J 2013:41:310-7.

15. Royal College of Obstetricians and Gynecologists. The care of woman requesting induced abortion, evidencebased clinical guideline, Vol 7. London: Royal College of Obstetricians and Gynecologists; 2004.

16. Singh K, Fong YF, Prasad RN, Dong F. Randomized trial to determine optimal dose of vaginal misoprostol for preabortion cervical priming. Obstet Gynecol 1998;92:795-8.

17. Ngai SW, Chan YM, Tang OS, Ho PC. The use of misoprostol for pre-operative cervical dilatation prior to vacuum aspiration: a randomized trial. Hum Reprod 1999;14:2139-42.

18. Radulovic N, Norström A, Ekerhovd E. Outpatient cervical ripening before first-trimester surgical abortion: a comparison between misoprostol and isosorbide mononitrate. Acta Obstet Gynecol Scand 2007;86:344-8.

19. Li CF, Chan CW, Ho PC. A comparison of isosorbide mononitrate and misoprostol cervical ripening before suction evacuation. Obstet Gynecol 2003;102:583-8.

20. Ei-Khayat W, Magad A, Omar H. A comparative study between isosorbide mononitate versus Misoprostol prior to hysteroscopy. Middle East Fertil Soc J 2010;15:27880.

21. Dhillon AP, Shergill HK, Yadav P. Comparative study between vaginal isosorbide mononitrate and misoprostol for induction of cervical ripening prior to surgical evacuation of first trimester embryonic demise. Int J Reprod Contracept Obstet Gynecol 2015;4:398-401.

22. Duhan N, Gupta S, Dahiya K, Sirohiwal D, Rohilla S. Comparison of isosorbide mononitrate and misoprostol for cervical ripening in termination of pregnancy between 8 and 12 weeks: a randomized controlled trial. Arch Gynecol Obstet 2011;283:1245-8. 